\title{
A prática da capoeira no ambiente escolar para a formação integral do aluno: uma revisão sistemática
}

\section{The practice of capoeira in the school environment for student integral formation:} A systematic review

\author{
Juliana Terra Ribeiro, Luis Felipe Milano Teixeira, Fabrício Teixeira Garramona \\ Universidade de Sorocaba (UNISO), Sorocaba, Brasil
}

\section{HISTÓRICO DO ARTIGO \\ Recebido: 01 maio 2021 \\ Revisado: 01 agosto 2021 \\ Aprovado: 10 agosto 2021}

\section{PALAVRAS-CHAVE:}

Capoeira; Educação Integral;

Educação Física; Escola;

Atividade Extracurricular.

\section{KEYWORDS:}

Capoeira; Integral Education; Physical Education; School; Extracurricular activity.

\section{RESUMO}

INTRODUÇÃO: A capoeira é considerada um dos maiores símbolos da cultura brasileira que mistura a arte marcial, o esporte, a cultura popular, a música e a dança. Por sua prática globalizada, a capoeira é um conteúdo a ser trabalhado no ambiente escolar visando a educação integral dos alunos, que por sua vez, está incluída na Base Nacional Comum Curricular.

OBJETIVO: Avaliar por meio de uma revisão sistemática se a prática da capoeira na escola pode contribuir para o desenvolvimento da educação integral dos alunos.

MÉTODOS: Uma busca sistemática utilizados termos relacionados a "Capoeira", "Educação Física" e "escola" foi realizada nos bancos de dados Periódico CAPES e Scielo, a fim de encontrar artigos elegíveis. Foram utilizados os seguintes critérios de inclusão: i) abordar a temática capoeira em suas diversas dimensões na escola; ii) apresentar a prática da capoeira inserida nas aulas de educação física ou como atividade extracurricular; iii) demonstrar os diferentes desenvolvimentos acerca dessa prática; iv) conciliar a capoeira com a educação integral. Após a seleção, foram extraídas informações sobre as características da amostra, intervenções utilizadas, grupos comparativos, resultados e conclusões, e uma análise descritiva dos resultados foi realizada. A escala PEDro (1999) foi utilizada para avaliar a qualidade dos estudos.

RESULTADOS: Foram incluídos um total de oito artigos, no qual dois enfatizaram o desenvolvimento físico/ motor e a inteligência corporal cinestésica, e os outros seis variaram apresentando aspectos físicos, sociais, culturais, cognitivos e afetivos. A análise de qualidade dos estudos demonstrou que dois artigos atingiram uma pontuação total de $3 / 10$, enquanto os demais obtiveram uma pontuação de $2 / 10$.

CONCLUSÃO: Os resultados apontaram que a prática da capoeira se demonstra como um instrumento positivo para o desenvolvimento da formação integral dos alunos, porém, deve-se considerar a baixa qualidade metodológica dos estudos incluídos.

\section{ABSTRACT}

BACKGROUND: Capoeira is considered one of the greatest symbols of Brazilian culture that mixes martial arts, sports, popular culture, music and dance. Due to its globalized practice, capoeira is a subject to be worked on in the school environment, aiming at the integral education of students, which in turn, is included in the Common National Curriculum Base.

OBJECTIVE: To evaluate, through a systematic review, whether the practice of capoeira at school can contribute to the development of integral education for students.

METHODS: A systematic search using terms related to "Capoeira", "Physical Education" and "school" was performed in the CAPES and Scielo journal databases, in order to find eligible articles. The following inclusion criteria were used: i) addressing capoeira in its various dimensions at school; ii) present the practice of capoeira as part of physical education classes or as an extracurricular activity; iii) demonstrate the different developments regarding this practice; iv) reconciling capoeira with integral education. After selection, information about the characteristics of the sample, interventions used, comparative groups, results and conclusions were extracted, and a descriptive analysis of the results was performed. The PEDro scale (1999) was used to assess the quality of studies.

RESULTS: A total of eight articles were included, in which two emphasized physical/motor development and kinesthetic body intelligence, and the other six varied with physical, social, cultural, cognitive and affective aspects. The quality analysis of the studies showed that two articles achieved a total score of $3 / 10$, while the others obtained a score of 2/10.

CONCLUSION: The results showed that the practice of capoeira is shown to be a positive instrument for the development of comprehensive training of students, however, the low methodological quality of the included studies must be considered. 


\section{INTRODUÇÃO}

A palavra capoeira é mencionada pela primeira vez por Bluteau (1712), em um livro publicado em Coimbra, Portugal, chamado Vocabulário Português e Latino, contudo, o termo ainda não se referia à capoeira que conhecemos atualmente, sendo o seu significado "gaiola de galinhas", e o capoeiro "aquele que furtava as galinhas da capoeira".

Não se sabe ao certo a origem da palavra, porém, foram muitas as tentativas da busca por sua descrição. Entre elas, podemos encontrar a proposta de essência tupi-guarani, demonstrada como caá-puêra, onde caá significa mato e puêra "aquilo que já se foi" (SOARES, 1880). Isso, diz respeito as matas do interior do Brasil, onde os indígenas praticavam a sua agricultura, além de ser utilizada como forma de refúgio para os escravos que eram perseguidos pelos capitães do mato. Já Rego (1968), estabelece o termo capoeira, como Kapuera, que se refere a uma roça abandonada, onde o mato já dominou.

Para Marinho (1956), a capoeira era praticada como forma de dança religiosa em Angola, antes mesmo de chegar ao Brasil. No entanto, Areias (1938), relata que ela surgiu pela luta e resistência dos escravos que eram tirados de suas terras e trazidos para o território brasileiro. Estes, descobriram em si a grande possibilidade de defesa contra o triste e revoltante cenário em que viviam, reproduzindo animais e manifestações trazidas da África.

Segundo Freitas (2013), a capoeira é considerada um dos maiores símbolos da cultura brasileira, que mistura a arte marcial, o esporte, a cultura popular, a dança e a música, apresentando delineamentos que se distinguem daqueles que foram a principal causa de sua origem. Para o autor, a cada dia que se passa é possível visualizar o seu processo de esportivização, tanto em academias que fornecem a sua prática, como a sua inclusão no âmbito educacional, demonstrando que ela pode ser vinculada ao ensino-aprendizagem, além de colaborar para a formação de indivíduos conscientes e críticos (FREITAS, 2013).

Sendo assim, é possível certificar a oportunidade de desenvolver a capoeira na escola como demonstra a lei 10639/03 que alterou a Lei de Diretrizes e Bases da Educação, incluindo no currículo oficial da rede de ensino a obrigatoriedade da temática "História e Cultura Afro-Brasileira e Africana" (LDB, 2003). Outra possibilidade de se trabalhar essa temática dentro do ambiente escolar, se dá pelo Projeto Mais Educação, "que visa fomentar a educação integral de crianças, adolescentes e jovens, por meio do apoio a atividades socioeducativas no contra turno escolar" (PORTARIA INTERMINISTERIAL, n¹7/2007, p. 5/6).

Contudo, a Base Nacional Comum Curricular, que se refere a um documento que determina as aprendizagens essenciais durante toda a educação básica, prevê que a educação física englobe os jogos, brincadeiras, danças, esportes, ginásticas e lutas, contendo também a cultura indígena, africana e tradicional (BNCC, 2017). Nesse sentido, a capoeira é um conteúdo a ser trabalhado nas escolas por sua prática globalizada que possibilita a arte, a luta, a educação, o esporte, o jogo, a dança, o folclore e o lazer. Segundo Paula e Bezerra (2014), a temática da capoeira pode apresentar o seu desenvolvimento integrado nas disciplinas de educação física, artes, geografia, história, literatura e geometria. Para os autores, em educação física desenvolve-se a prática da capoeira propriamente dita; em artes os estudos relacionados as obras de Johann Moritz Rugendas, por exemplo, que viajou pelo Brasil durante o período de 1822 a 1825, expressando por meio de suas pinturas os costumes e povos encontrados por ele, e a música popular brasileira como Baden Powell e Vinicius de Moraes, com o samba "berimbau", ou até mesmo as músicas cantadas na capoeira que carregam grande bagagem histórica; em geografia a localização do continente africano, o percurso do navio negreiro até a sua chegada no Brasil, o desenvolvimento humano e a economia no período da escravidão; em história a abordagem de temas como quilombos, navio negreiro, escravidão e abolição; em literatura com as obras de Jorge Amado e Manuel Antônio de Almeida; e em geometria a construção do conceito de circunferência, ângulo e grau, utilizando dos movimentos corporais da capoeira.

De acordo com Serbelo (2020), algumas das competências que a capoeira é capaz de favorecer, são: o conhecimento da história do nosso país que são transmitidos por meio das músicas, histórias e relatos dos mestres mais antigos; e o autoconhecimento e autocuidado, percebendo o seu limite na realização de um movimento, além de zelar pela integridade física de si próprio e dos colegas já que em uma roda de capoeira você não joga "contra o seu amigo", e sim "com o seu amigo", o que permite o desenvolvimento de sentidos cognitivos e motores dos praticantes. Colaborando com essa ideia, Paula e Bezerra (2014) afirmam que a capoeira praticada na escola possui como benefício o aumento do equilíbrio, da coordenação, da associação visual motora, da orientação espacial, da lateralidade, da criatividade, da direcionalidade e uma relação mais saudável do indivíduo com a sua autoimagem.

Outro ponto muito importante a se destacar presente na BNCC é a educação integral, que entende que a educação deve garantir o desenvolvimento dos indivíduos em todas as suas dimensões, sejam elas físicas, emocionais, intelectuais, culturais e sociais. Essa proposta deve se pautar em um projeto coletivo, envolvendo a participação de crianças, jovens, educadores, gestores, familiares e comunidades locais, sendo a escola o espaço primordial para certificar que todos tenham uma formação integral (BNCC, 2017).

Contudo, ainda não é claro na literatura se a inserção da capoeira no ambiente escolar é capaz de auxiliar na formação integral dos alunos da educação básica. Dessa forma, o objetivo do presente estudo foi avaliar, através de uma revisão sistemática, se a prática da capoeira no ambiente escolar pode contribuir para o desenvolvimento da educação integral dos alunos, possibilitando a diversidade de experiências e situações, independente da fase em que eles se encontram.

\section{MÉTODOS}

Com a finalidade de eleger estudos relevantes para esta pesquisa, uma busca sistemática foi realizada no banco de dados Periódico CAPES e Scielo em agosto de 2020, usando os seguintes descritores: Capoeira e Educação Física; Capoeira e Escola; e Capoeira e Educação Integral. Não houve limitação de data de publicação ou restrição de idioma.

As referências encontradas por meio da busca sistemática foram analisadas individualmente com a finalidade de detectar os estudos elegíveis para esta pesquisa e, para isso, os seguintes critérios de inclusão/exclusão foram adotados, a saber: 
Critérios de inclusão: i) abordar a temática capoeira em suas diversas dimensões na escola; ii) apresentar a prática da capoeira inserida nas aulas de educação física ou como atividade extracurricular; iii) demonstrar os diferentes desenvolvimentos acerca dessa prática; iv) conciliar a capoeira com a educação integral.

Critérios de exclusão: i) estudos pilotos, artigos de opinião ou revisão; ii) inclusão da prática de outras modalidades de luta que não a capoeira; iii) estudos que não envolvessem.

Um dos autores (JCR) avaliou individualmente os títulos e os resumos de todos os estudos encontrados para deferir a sua elegibilidade para este estudo. Resumos que não apresentavam dados suficientes para responder os critérios de inclusão/exclusão, foram analisados pelo seu texto completo. Um segundo autor (FTG) revisou o processo de seleção para garantir a acurácia do processo.

Uma planilha foi planejada previamente pelos autores com as informações que seriam coletadas e utilizadas para a análise. Um autor (JTR) realizou o processo de extração dos dados, e um terceiro autor (LFMT) revisou o processo de extração. Foram extraídas informações sobre as características da amostra, intervenções utilizadas, grupos comparativos, resultados e conclusões.

Por fim, realizou-se uma análise descritiva, que se baseia na descrição detalhada dos fatos, seguida da interpretação dos dados, explorando as possibilidades frente aos interesses da formação integral dos sujeitos, partindo das experiências das aulas de capoeira na escola. Além disso, foi realizado a análise da qualidade dos estudos incluídos por meio da escala PEDro
(1999), usando, prioritariamente, os resultados disponíveis na plataforma. Os estudos não inclusos na plataforma foram avaliados manualmente por dois pesquisadores (JTR e FTG).

\section{RESULTADOS E DISCUSSÃO}

Durante a realização da pesquisa no banco de dados Periódico CAPES e Scielo, foram encontrados um total de 450 artigos, porém, com a exclusão de estudos duplicados, ficaram 315. Após a leitura dos títulos e resumos, como uma primeira avaliação, 17 foram selecionados (Figura 1). Entretanto, através da leitura aprofundada de cada artigo, apenas 8 foram incluídos nesta análise (Quadro 1).

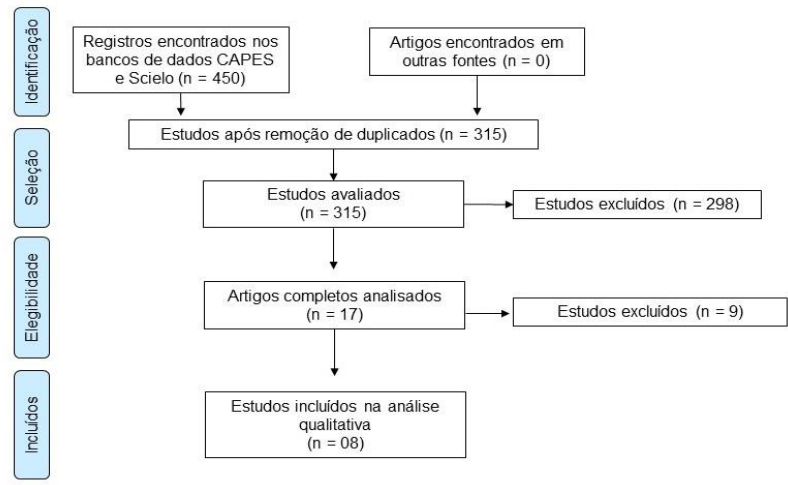

Figura 1. Fluxograma do percurso metodológico adotado para a busca das publicações.

Quadro 1. Estudos avaliados sobre Capoeira nos periódicos científicos publicados e localizados no Portal de Periódicos da CAPES e na Base Scielo até maio de 2021.

\begin{tabular}{|c|c|c|c|c|}
\hline Autor (Ano) & Objetivo & Tamanho da Amostra & Intervenção & Conclusão \\
\hline $\begin{array}{l}\text { Castro Junior et al. } \\
\text { (2000) }\end{array}$ & $\begin{array}{l}\text { Discutir a importância da capoeira } \\
\text { enquanto instrumento pedagógico, } \\
\text { demonstrando o festival de capoeira } \\
\text { da escola }\end{array}$ & $\begin{array}{l}500 \text { crianças e adolescentes de } \\
\text { ambos os sexos }\end{array}$ & $\begin{array}{l}3 \text { anos de festival de capoeira na escola, } \\
\text { reunindo alunos de } 4 \text { escolas púbicas, inves- } \\
\text { tigando a integração e troca de experiência } \\
\text { entre eles }\end{array}$ & $\begin{array}{l}\text { O festival se demonstrou como possibilidade de } \\
\text { construção de um espaço de integração, formação e } \\
\text { aprendizagem, ressaltando a valorização da cultura e } \\
\text { históriaa, além da construção de identidade e troca de } \\
\text { experiência dos alunos. }\end{array}$ \\
\hline $\begin{array}{l}\text { Carneiro e } \\
\text { Garcia Júnior } \\
\text { (2010) }\end{array}$ & $\begin{array}{l}\text { Verificar o efeito da aprendizagem } \\
\text { da capoeira por meio de atividades } \\
\text { lúdicas sobre capacidades físicas de } \\
\text { pré-escolares }\end{array}$ & $\begin{array}{l}10 \text { crianças: } 8 \text { meninos e } 2 \\
\text { meninas ( } 5 \text { e } 6 \text { anos) }\end{array}$ & $\begin{array}{l}12 \text { semanas de aulas, } 2 x / \text { semana ( } 50 \mathrm{~min} \text { ); } \\
\text { as capacidades físicas foram avaliadas por } \\
\text { meio de testes de flexibilidade, potência de } \\
\text { membros inferiores, equilíbrio e agilidade }\end{array}$ & $\begin{array}{l}\text { Os resultados permitiram concluir que a aprendizagem } \\
\text { da capoeira por meio de atividades lúdicas proporciona } \\
\text { a melhora de capacidades físicas em crianças. }\end{array}$ \\
\hline $\begin{array}{l}\text { Valdes } \\
\text { (2015) }\end{array}$ & $\begin{array}{l}\text { Discutir a importância da capoeira } \\
\text { como instrumento pedagógico de } \\
\text { inclusão social, por meio da disciplina } \\
\text { de educação física, visando desenvol- } \\
\text { ver umaa progressão metodológica de } \\
\text { aprendizagem da capoeira }\end{array}$ & $\begin{array}{l}\text { Alunos do } 1^{\circ} \text { ao } 6^{\circ} \text { ano do E. F. } \\
\text { ( } 1 \text { hora por semana por sala, } \\
\text { com matrículas de } 17 \text { a } 25 \\
\text { alunos por classe) }\end{array}$ & $\begin{array}{l}8 \text { sessões. } \\
\text { O tempo da prática foi de } 100 \text { horas, distri- } \\
\text { buídas em } 12 \text { horas semanais, com } 3 \text { horas } \\
\text { diárias de permanência na escola (segunda } \\
\text { a quinta-feira). }\end{array}$ & $\begin{array}{l}\text { A capoeira demonstrou-se com um complemento } \\
\text { concreto, real e inovador para a escola. Também serviu } \\
\text { para esclarecer a abordagem curricular, podendo ser } \\
\text { inserida no planejamento por meio de diversos jogos } \\
\text { e atividades. }\end{array}$ \\
\hline $\begin{array}{l}\text { Barros } \\
(2015)\end{array}$ & $\begin{array}{l}\text { Verificar a alteração da inteligência } \\
\text { cinestésica dos alunos do ensino } \\
\text { médio, durante as aulas de Educação } \\
\text { Física escolar com a prática da moda- } \\
\text { lidade capoeira }\end{array}$ & $\begin{array}{l}6 \text { alunos do ensino médio } \\
\text { ( } 4 \text { meninos e } 2 \text { meninas) }\end{array}$ & $\begin{array}{l}8 \text { aulas ( } 50 \mathrm{~min} \text { ), durante } 4 \text { semanas. } \\
\text { Foram aplicadas três autoavaliações por } \\
\text { questionário fechado (escala de percepção } \\
\text { subjetiva do aprendizado) }\end{array}$ & $\begin{array}{l}\text { O estudo revelou um pequeno desenvolvimento da } \\
\text { Inteligência Corporal Cinestésica. }\end{array}$ \\
\hline $\begin{array}{l}\text { Martins et al. } \\
(2016)\end{array}$ & $\begin{array}{l}\text { Demonstrar como o protagonismo } \\
\text { das crianças se manifestou nas } \\
\text { aulas de educação física e como as } \\
\text { intervençõ̂es pedagógicas foram } \\
\text { conduzidas pelos bolsistas }\end{array}$ & $\begin{array}{l}3 \text { bolsistas de iniciação à } \\
\text { docência (ID), } 1 \text { professor-su- } \\
\text { pervisor e } 25 \text { crianças }\end{array}$ & $\begin{array}{l}30 \text { aulas (set - dez). } \\
\text { As práticas foram analisadas através da pes- } \\
\text { quisa-ação colaborativa com a metodologia } \\
\text { participativa, além de registros fotográficos } \\
\text { e desenhos, extraídos de uma vivência } \\
\text { pedagógica }\end{array}$ & $\begin{array}{l}\text { O professor ajudou as crianças a transformar e produzir } \\
\text { cultura, assumindo o papel de mediador da aprendi- } \\
\text { zagem. Também cumpriu com o papel de interação e } \\
\text { motivação, valorizando a relação com a criança.A capo- } \\
\text { eira contribuiu para a construção da nova concepção de } \\
\text { infância na formação dos adultos envolvidos. }\end{array}$ \\
\hline $\begin{array}{l}\text { Caetano et al. } \\
\text { (2018) }\end{array}$ & $\begin{array}{l}\text { Conhecer as possíveis contribuições } \\
\text { que a prática da capoeira como } \\
\text { atividade física regular traz ao com- } \\
\text { portamento dos alunos no ambiente } \\
\text { escolar, na visão do professor }\end{array}$ & $\begin{array}{l}11 \text { professores e alunos de } 5 \\
\text { a } 7 \text { anos que já praticavam a } \\
\text { capoeira na escola }\end{array}$ & $\begin{array}{l}\text { Pesquisa qualitativa-quantitativa: } \\
\text { aplicação de questionário investigativo } \\
\text { (perguntas objetivas e abertas sobre a visão } \\
\text { geral do problema da pesquisa) }\end{array}$ & $\begin{array}{l}\text { Melhora do comportamento dos alunos, na visão dos } \\
\text { professores. Mostrou-se um instrumento educacional, } \\
\text { contribuindo com os aspectos motores, de socialização, } \\
\text { valores, além de auxiliar na formação integral da } \\
\text { criança. }\end{array}$ \\
\hline $\begin{array}{l}\text { Gorito e Alves } \\
\text { (2019) }\end{array}$ & $\begin{array}{l}\text { Investigar as possíveis contribuições } \\
\text { das práticas socioculturais desenvolvi- } \\
\text { das pela capoeira }\end{array}$ & $\begin{array}{l}\text { Estudantes entre } 08 \text { e } 16 \\
\text { anos, separando-os em duas } \\
\text { turmas: de } 8 \text { a } 11 \text { anos, e de } \\
12 \text { a } 16 \text { anos }\end{array}$ & $\begin{array}{l}\text { Aulas às quintas-feiras (14h-16h). } \\
\text { Instrumento investigativo: diário de bordo, } \\
\text { roda de conversa e "conversa com café" } \\
\text { com os responsáveis }\end{array}$ & $\begin{array}{l}\text { A capoeira permitiu momentos de lazer e reflexão, } \\
\text { fortaleceu as relações em grupo, ocorrendo mudança de } \\
\text { comportamento nos estudantes, tais como companhei- } \\
\text { rismo, cooperação, paciência, disciplina, autocontrole } \\
\text { etc. }\end{array}$ \\
\hline
\end{tabular}


A análise de qualidade dos estudos incluídos foi realizada através da escala PEDro (1999). Após a análise, o estudo de Carneiro e Garcia Júnior (2012) e de Barros (2015) atingiram uma pontuação total de $3 / 10$, enquanto os demais estudos apresentaram uma pontuação de 2/10, como demonstrado no Quadro 2.

A prática da capoeira inserida no ambiente escolar pode ser visualizada a partir das aulas de educação física ou por meio de atividades extracurriculares, como demonstrado nos estudos selecionados. No entanto, buscou-se avaliar a prática da capoeira para a formação integral dos alunos, por meio de uma revisão sistemática. Este, incluiu oito artigos em que dois dão ênfase ao desenvolvimento físico/motor, junto da inteligência corporal cinestésica, escritos por Carneiro e Garcia Júnior (2010); e Barros (2015), que obtiveram um melhor score no quesito de qualidade na escala PEDro. Entretanto, os demais estudos apresentados por Castro Júnior et al. (2000), Souza et al. (2012), Valdes (2015), Martins et al. (2016), Caetano et al. (2018) e Gorito e Alves (2019), variam de acordo com os aspectos físicos, sociais, culturais, cognitivos e afetivos, obtendo um score de $2 / 10$ na escala PEDro.

Para Carneiro e Garcia Júnior (2010), a aprendizagem da capoeira ao decorrer da infância deve ser desenvolvida de maneira recreativa, sem especializar quaisquer movimentos, principalmente quando nos referimos aqueles com menos de seis anos de idade, pois nessa fase deve-se resgatar a satisfação do praticante por meio do ensino, e não a técnica e perfeição do mesmo. Sendo assim, esse estudo visualizou a evolução das capacidades físicas em crianças, a partir da prática da modalidade, demonstrando um aumento de $26 \%$ na flexibilidade, $20 \%$ na impulsão vertical, $87,2 \%$ no equilíbrio e $21 \%$ na agilidade, levando em consideração que o período de realização dessa intervenção foi de 12 semanas. Os autores também destacaram o aumento da amplitude, maior qualidade na transição de movimentos, maior consistência na realização repetida e na capacidade de realizar sequências de movimentos, quando comparado os resultados da primeira semana de prática e após o término das aulas.

Outro estudo realizado por Barros (2015), verificou as alterações da inteligência corporal cinestésica em alunos do ensino médio partindo da prática da modalidade de capoeira. A inte- ligência corporal cinestésica, por sua vez, é expressa na Teoria das Inteligências Múltiplas proposta por Gardner (1980), e consiste na capacidade de utilizarmos o nosso corpo como instrumento para a resolução de situações-problema.

Neste mesmo estudo (BARROS, 2015), as alterações foram percebidas pelo autor através da Escala de Percepção Subjetiva do Aprendizado utilizando a estatística descritiva em três avaliações onde a média e desvio padrão da primeira avaliação, respectivamente, foi de 8,33 e 0,82 , na segunda avaliação 8,83 e 0,41 , e na terceira avaliação 8,67 e 1,21 . Quanto mais próximo fossem os valores nas três avaliações, mais satisfatório era o resultado, pois demonstrava que as aulas mantiveram um equilíbrio na aprendizagem de forma constante na visão dos alunos.

Segundo o autor a realização da Escala de Percepção Subjetiva do Aprendizado tem por finalidade fazer com que o aluno reflita o quão ele foi capaz de compreender, executar e relacionar aquilo que lhe foi passado com o conhecimento adquirido, combinando as sensações das capacidades coordenativas, capacidade de coordenação motora (grossa) e capacidade de equilíbrio (dinâmico). O estudante avaliou a sua sensação de aprendizado com honestidade sem levar em conta o seu condicionamento físico atual ou qualquer tipo de comparação entre os demais participantes. Por fim, os dados coletados demonstraram que os alunos se classificaram na escala a partir dos números representados por $7,8,9$ e 10, em que os três primeiros indicam que eles compreenderam bastante, e o último, que compreenderam totalmente. Com isso o autor conclui que apesar de as alterações terem sido percebidas por uma medida subjetiva, elas podem apresentar uma estimativa bastante relevante do entendimento dos alunos sobre as aulas, no qual para ele, os resultados indicaram que houve o desenvolvimento da inteligência corporal cinestésica.

Contudo, no estudo escrito por Valdes (2015) buscou-se destacar a importância da capoeira como instrumento pedagógico de inclusão no ambiente escolar por meio da disciplina de educação física. $\mathrm{O}$ autor relata que as artes corporais permitem a ocorrência de transformação humana individual dentro de um coletivo. Nesse sentido, aspectos como a promoção da saúde, saberes, valores e hábitos para o cuidado com as relações interpessoais e intrapessoais, corporeidade e autoestima foram debatidos. Seu foco se baseou em resgatar os pontos citados em

Quadro 2. Avaliação da qualidade dos estudos, avaliados por meio da Escala PEDro (1999).

\begin{tabular}{|c|c|c|c|c|c|c|c|c|}
\hline Escala PEDro & $\begin{array}{l}\text { Castro Jr. } \\
\text { et al. (2000) }\end{array}$ & $\begin{array}{c}\text { Carneiro e } \\
\text { Garcia Jr. (2010) }\end{array}$ & $\begin{array}{l}\text { Souza et al. } \\
\text { (2012) }\end{array}$ & Valdes (2015) & Barros (2015) & $\begin{array}{l}\text { Martins et al. } \\
\quad(2016)\end{array}$ & $\begin{array}{l}\text { Caetano et al. } \\
\text { (2018) }\end{array}$ & $\begin{array}{l}\text { Gorito e Alves } \\
\text { (2019) }\end{array}$ \\
\hline Critérios de elegibilidade* & - & - & - & - & - & - & - & - \\
\hline Alocação aleatória & - & - & - & - & - & - & - & - \\
\hline Alocação secreta & - & - & - & - & - & - & - & - \\
\hline Comparabilidade de linha de base & - & - & - & - & - & - & - & - \\
\hline Sujeito cego & - & - & - & - & - & - & - & - \\
\hline Avaliador cego & - & - & - & - & - & - & - & - \\
\hline Acompanhamento adequado & Sim & Sim & Sim & Sim & Sim & Sim & Sim & Sim \\
\hline Intenção de tratar análise & - & - & - & - & - & - & - & - \\
\hline Comparação entre grupos & Sim & Sim & Sim & Sim & Sim & Sim & Sim & Sim \\
\hline Estimativas pontuais e variabilidade & - & Sim & - & - & Sim & - & - & - \\
\hline TOTAL & $2 / 10$ & $3 / 10$ & $2 / 10$ & $2 / 10$ & $3 / 10$ & $2 / 10$ & $2 / 10$ & $2 / 10$ \\
\hline
\end{tabular}

*O item critérios de elegibilidade não contribuí para a pontuação total. 
crianças e jovens marginalizados que se encontram em contexto de risco social, onde a maioria das famílias da escola são monoparentais, com problemas financeiros, deficiências emocionais, sociais e culturais. O trabalho de Valdes (2015) se baseou nas ideias propostas por Olaechea e Georg (2007) que destaca que os fatos artísticos possuem características transformadoras de enxergar e interpretar o mundo em suas diferentes formas, permitindo que os protagonistas desses cenários se tornem criadores de novas realidades em seus próprios espaços comunitários.

Dessa forma, Valdes (2015) realizou uma intervenção com os alunos do $1^{\circ}$ ao $6^{\circ}$ ano do ensino fundamental em que o tempo de prática foi de 100 horas totais (de segunda a quinta-feira). Durante cada aula as impressões da turma, os resultados das atividades, o cumprimento dos objetivos e a participação dos alunos foram acompanhados através de um diário de bordo. Os estudantes também realizaram os seus registros respondendo as seguintes perguntas: "o que eu aprendi hoje?" e "o que eu mais gostei e não gostei de fazer nas aulas?". O autor relatou que os alunos conheceram e aprenderam a capoeira brincando; a mudança de comportamentos e relacionamentos positivos; um aumento da disposição dos indivíduos para trabalhar em grupos, acolhendo e valorizando os colegas e sua individualidade; o entendimento por parte dos estudantes de que se todos colaborarem uns com ou outros, alcançando pequenas conquistas, todo o grupo cresce e ganha; e que a avaliação do trabalho de criatividade e expressão corporal foram os momentos de maior aprendizagem significativa para os alunos.

Valdes (2015) ressalta que a capoeira é capaz de fornecer o autoconhecimento da corporeidade e a criação de formas de expressão através da possibilidade de comunicação não verbal, e que pelo contato corporal além da força e energia, os componentes afetivos e emocionais também são transmitidos. Ademais, o autor relata que a criatividade está muito ligada a expressão corporal e corporeidade já que nessa modalidade está inserida a estratégia de unir a energia do movimento do outro para dar continuidade ao jogo, ou seja, os indivíduos agem de acordo com o que o outro faz, sendo muito comum o encontro de situações imprevistas fazendo com que novos movimentos apareçam e que consigamos ser flexíveis ao ponto de lidar com improvisações.

Além disto, durante a roda de capoeira um mesmo indivíduo assume diferentes funções, ou seja, "dependendo do momento, ele poderá ser um jogador ativo, observador, cantor, músico e artista" (VALDES, 2015, p. 9). A execução dos instrumentos representa o começo da roda onde logo após o som do berimbau, atabaque, pandeiro e agogô, o canto se inicia e é acompanhado de palmas que devem estar em sintonia com os instrumentos e pelo coro enérgico de todas as pessoas que ali se encontram. $\mathrm{O}$ jogo da capoeira acontece entre dois jogadores que realizam a todo momento a troca de diálogo corporal representados através dos movimentos de ataque, defesa, contra-ataque, acrobacias, olhares, símbolos e expressão corporal, influenciados diretamente pelo ritmo da música. As cantigas cantadas direcionam a energia aplicada na roda ao mesmo tempo que conduzem os jogos, sendo que a ideia emitida pela música irá determinar aquilo que os corpos transmitem. Nesse sentido, a música desempenha um importante papel motivador das ações, que marca a cadência e consequentemente, a velocidade em que os golpes e esquivas serão realizados. A estratégia de jogo em que os indivíduos irão adotar dependerá de seu oponente, basean- do-se em sua altura, peso, habilidade, experiência e visão de jogo, ou seja, deve-se conhecer a si mesmo e ao outro.

Suas principais características educacionais de acordo com Valdes (2015) é a capacidade de se trabalhar os valores humanos, o que contribui para a formação de cada um como cidadão. Para o autor, a convivência de forma diversificada é permitida, então os alunos interagem uns com os outros respeitando a individualidade e diferença entre eles. Existe também a importância de se atentar à integridade física e emocional dos praticantes, no qual todos são vistos como valiosos e insubstituíveis dentro do grupo. Por fim, alguns exemplos de símbolos que desenvolvem valores dentro da capoeira são citados no estudo, como a "saudação" no início e ao final do jogo que demonstra o respeito e cordialidade entre os dois jogadores, a "volta ao mundo" em que um dos jogadores convida o outro para caminhar ao redor da roda em momentos de fadiga manifestando o entendimento de limite do seu oponente, o "sistema de compra" visando uma melhor organização do ambiente e dos jogos e a colaboração de todos os outros participantes que estão observando, batendo palma, tocando os instrumentos e cantando, pois sem eles, a roda de capoeira não aconteceria.

O estudo de Gorito e Alves (2019) tem como finalidade investigar as possíveis contribuições das práticas socioculturais desenvolvidas pela capoeira, utilizando como instrumento de busca dos dados as rodas de conversas e diário de bordo com a intenção de apreender os registros, acontecimentos e modos comportamentais dos alunos. Durante a apresentação do estudo algumas falas são expostas nas quais correspondem às visões dos alunos, responsáveis e docentes da escola. Desse modo, quando o professor perguntou aos alunos o que é a capoeira eles responderam que é a maneira com que os escravos se defendiam e uma dança para esquecer o sofrimento, destacando também que com essa prática é possível aprender a história. Em uma segunda pergunta sobre o que Ihes chamou mais a atenção desde que iniciaram o projeto, é ressaltado pelos estudantes o dia em que participaram de uma roda de capoeira fora do ambiente de costume, os aprendizados sobre o contexto histórico da prática, e o tempo, que segundo o aluno, na capoeira passa mais rápido.

Sendo assim, Gorito e Alves (2019), discorrem que a capoeira permitiu momentos de lazer e reflexão aos alunos, fortaleceu as relações em grupo e de respeito mútuo entre eles, que foi notável as mudanças comportamentais como o autocontrole, disciplina, paciência, companheirismo, dinamismo, assiduidade e tomada de decisão, e que as experiências obtidas através da prática da modalidade, repercutiram em outros espaços. Dentre os aspectos citados, o comentário de um dos responsáveis de determinado aluno do projeto corroborou com o argumento dos autores ao afirmar que depois que o filho iniciou a prática da capoeira as suas notas aumentaram nos demais componentes curriculares da escola. Além disso, Gorito e Alves (2019) pontuaram que os professores relataram uma maior participação dos alunos nas aulas, o aumento do desempenho nas avaliações, o estudo levado mais a sério, além da organização dos estudantes com os seus materiais. Os autores ainda apontaram a visão de um dos docentes que declara que esses resultados eram frutos do suporte do projeto, que incentiva os alunos a terem mais disciplina, respeito, ordem e organização. Esses achados vão ao encontro do relatado por Falcão (2004), que discorre que todas as mudanças que estão relacionadas aos aspectos atitudinais e 
154 RIBEIRO et al.

A prática da capoeira no ambiente escolar para a formação integral do aluno: uma revisão sistemática

de comportamento do indivíduo, podem, de maneira significativa influenciar outras questões.

Outro estudo que demonstrou a participação de pais e alunos foi realizado por Souza et al. (2012) através de uma pesquisa-ação que teve a durabilidade de dez meses. Este, apresentou resultados semelhantes ao estudo anterior (GORITO; ALVES, 2019), onde foi possível a construção dos conceitos ligados à lealdade, respeito, disciplina e de afetividade nos estudantes do $3^{\circ}$ ano do ensino fundamental.

Os autores citaram que ao decorrer das aulas os alunos são capazes de se expressar e até mesmo descobrir novos movimentos, sendo esse ato resultado da liberdade que a capoeira fornece aos seus praticantes, englobando também movimentos acrobáticos, seu contexto histórico, o afeto social, além da possibilidade do contato dos estudantes com as danças folclóricas, como a puxada de rede, dança guerreira e maculelê.

Ao trabalhar a capoeira, Souza et al. (2012) relataram que os responsáveis pelos alunos não conheciam a dimensão pedagógica, cognitiva, físico-motor, social e disciplinador que essa modalidade desenvolve em seus praticantes dentro de um ambiente de socialização. No entanto, após a finalização do projeto, foram capazes de conciliá-las às mudanças de comportamento, maior concentração, comunicação, equilíbrio emocional e até a capoeira como filosofia de vida, onde existem regras e disciplinas a serem seguidas.

Contudo, com o objetivo de conhecer as possíveis colaborações da capoeira, Caetano et al. (2018) realizaram uma pesquisa com onze professores de uma escola, que possuem como alunos crianças de cinco a sete anos que praticam a capoeira no regime regular. A coleta dos dados foi realizada por meio da aplicação de um questionário investigativo que continham perguntas abertas e fechadas sobre a visão dos professores da temática. Os autores concluíram que a capoeira favorece a coordenação motora, a construção do conhecimento, a boa convivência, valores e a formação integral do aluno, levando em consideração que a mesma deve ser trabalhada de forma que respeite as fases maturacionais e de desenvolvimento motor dos indivíduos.

A capoeira na visão de Castro Júnior et al. (2000), atua como espaço de exercício da cidadania, de autonomia, autoestima e de construção de identidade, priorizando uma educação consciente e libertadora. Nesse sentido, os autores trazem a experiência do festival de capoeira da escola contando com a participação de crianças e adolescentes de quatro instituições diferentes.

O festival foi dividido em quatro momentos: a roda de capoeira, apresentações culturais, oficinas orientadas pelos mestres e a confraternização, partindo do princípio de que "ao invés do atleta, o Capoeirista, ao invés da competição, a cooperação, ao invés da disputa, a confraternização, ao invés da medalha, e lembrança e ao invés do jogo contra o adversário, o jogo com o parceiro" (CASTRO JÚNIOR et al., 2000, p. 10).

Para eles, a roda de capoeira representa um dos momentos de mais importância, pois ela demonstra a manifestação da cultura e expressão de um povo onde existem regras e fundamentos a serem seguidos, além dos indivíduos poderem desenvolver as suas habilidades e demonstrarem tudo o que aprenderam durante os treinos. Os jogos foram supervisionados por dois professores e os alunos jogavam com estudantes de outras escolas. O segundo momento em que aconteceram as apresentações culturais, foi valorizado o trabalho e criatividade de cada instituição. Os alunos representaram movimentos sociais de luta e resistência, danças, literatura de cordel, entre outros. O terceiro momento de oficinas pedagógicas foi dividido de modo em que cada mestre de capoeira se responsabilizou por um tema como, por exemplo, a construção de instrumentos de percussão, do berimbau, e a vivência da capoeira angola e regional, em que seus conhecimentos eram aprofundados tanto de maneira teórica, como prática. Por fim, no quarto momento todos os participantes realizaram uma confraternização, finalizando o evento.

Os autores relembraram o fato de que o festival aconteceu em três anos, um seguido do outro, e teve durabilidade de três dias cada um. O primeiro evento contou com a participação de 500 crianças e adolescentes, o segundo aproximadamente 800 e o terceiro, atingiu praticamente 1000 estudantes, sendo que nesse ano foram exibidos filmes e documentários sobre a capoeira e vídeos de festivais anteriores. Através dessa experiência concluíram que o festival teve como resultado a integração e troca de experiência entre os alunos das diferentes escolas, afirmando a importância da valorização dessa expressão cultural para os indivíduos locais na construção da autoestima, identidade e da cidadania.

O estudo realizado por Martins et al. (2016) teve por finalidade descrever como o protagonismo infantil se manifesta nas aulas de educação física com as intervenções pedagógicas conduzidas pelos bolsistas do PIBID e de um professor-supervisor, com 25 crianças. Os dados obtidos durante o período de 15 semanas de aula de capoeira foram entendidos através da observação de participação, fotografias e desenhos realizados pelos alunos.

As práticas pedagógicas comandadas pelos bolsistas consistiram em apresentar a temática de capoeira, porém, partindo de brincadeiras adaptadas. Os professores analisaram a reação das crianças, o que facilitou a identificação de seus interesses, desejos e motivações.

Após as experiências vividas na disciplina de educação física, os professores visualizaram os alunos no pátio da escola realizando os movimentos aprendidos nas aulas anteriores, e logo após, jogando capoeira entre eles mesmo sem a intervenção de um responsável. Isso, para Martins et al. (2016) demonstrou o exemplo da ampliação do repertório cultural das crianças, a manifestação das suas preferências quanto as temáticas e conteúdos trabalhados nas aulas, e que de alguma maneira, as práticas foram significativas para eles.

Outra forma de compreender a participação dos alunos foi por meio da análise dos desenhos produzidos, onde os estudantes realizaram a representação das aulas de capoeira demonstrando os instrumentos utilizados, os movimentos, os professores e o momento da roda. Para os autores, ao desenhar a criança é capaz de contar a sua história, compartilhar seus pensamentos, fantasias e sentimentos. Esse ato faz com que o indivíduo seja capaz de interagir com o meio em que está inserido demonstrando o seu papel como pessoa e o como os diversos aspectos que o rodeiam são representados e interpretados.

Embora os artigos selecionados nos mostrem a efetividade da prática da capoeira no ambiente escolar para a formação integral dos alunos como a sua colaboração para os aspectos 
físicos, culturais, cognitivos, afetivos/emocionais e sociais, vale ressaltar algumas limitações dos trabalhos analisados. De modo geral, é perceptível a falha metodológica presente nos estudos onde os autores poderiam ser mais criteriosos na escolha utilizada para a interpretação dos dados obtidos a partir da pesquisa de campo, pois a grande maioria opta por partir do princípio de análise de dados subjetivos. Além disso, podemos notar a inexistência dos grupos comparativos o que agregaria uma maior qualidade aos estudos, demonstrando as semelhanças e diferenças entre eles ao decorrer do desenvolvimento das intervenções e garantindo um resultado mais preciso e seguro. Todas essas limitações ficam evidentes nos resultados observados através da avaliação pela escala PEDro.

Outra limitação observada em determinados estudos se baseia na exposição dos resultados, constatando-se a omissão e/ Ou a falta na clareza dos dados, os quais não foram compartilhados em sua totalidade. Isso é certificado nos estudos que possuem a participação de pais/responsáveis e professores, junto dos alunos à base de entrevistas, ou como demonstra o trabalho de Martins et al. (2016), sendo que de 25 crianças, apenas dois desenhos são expostos (levando em consideração que a análise dessas produções é levantada como critério de avaliação para a observação da manifestação do protagonismo infantil nas aulas de educação física).

Possivelmente a baixa qualidade metodológica dos estudos selecionados se apresenta principalmente pelo fato de que a maior parte dos trabalhos desenvolvidos no contexto escolar nascem como projetos sociais para atender a comunidade local e acabam posteriormente sendo relatados como pesquisa científica. Desse modo, sugere-se que novos estudos randomizados e controlados sobre a capoeira no ambiente escolar demonstrando os seus desenvolvimentos nas diversas dimensões, sejam realizados.

O presente estudo apresenta algumas limitações. O pequeno número de banco de dados utilizados para a busca, os quais foram limitados devido ao perfil da pesquisa. Embora seja preconizado pelo "Preferred Reporting Items for Systematic Reviews and Meta-Analysis" (PRISMA) o presente estudo não possui registro na plataforma PROSPERO, bem como, a etapa de busca e seleção dos artigos não foi realizada de forma duplicada e independente. Além disso, a heterogeneidade presente nos estudos incluídos limitou a análise descritiva dos estudos.

\section{CONCLUSÃO}

Como visualizado ao decorrer do estudo, a Base Nacional Comum Curricular (2017) prevê que a disciplina de educação física englobe os jogos, brincadeiras, danças, esportes, ginásticas e lutas, contendo também a cultura indígena, africana e tradicional. No entanto a capoeira se demonstra como um conteúdo globalizado justamente por atender a esses requisitos, além da possibilidade do seu desenvolvimento nas diversas disciplinas, como: educação física, artes, história, geometria, literatura e geografia.

Nos estudos selecionados, os resultados obtidos apontam para a efetividade da prática da capoeira na escola como ferramenta auxiliar para a formação humana dos alunos, pois através da capoeira foi possível trabalhar os aspectos físicos, sociais, afetivos/emocionais, culturais e cognitivos. Sendo assim, os au- tores Carneiro e Garcia Júnior (2010) e Barros (2015) buscaram transmitir por meio de suas intervenções os benefícios ligados ao aspecto físico/motor e de inteligência corporal cinestésica. Desse modo, foi visualizado a evolução das capacidades físicas nos alunos praticantes de capoeira demonstrando o aumento de flexibilidade, equilíbrio, agilidade, amplitude, maior qualidade na sequência e transição de movimentos e a capacidade da utilização do corpo como instrumento de resolução de situações-problema. Por sua vez, Castro Junior et al. (2000), Souza et al. (2012), Valdes (2015), Martins et al. (2016), Caetano et al. (2018) e Gorito e Alves (2019) trouxeram maiores detalhes referente as dimensões físicas, sociais, cognitivas e afetivas. Para Valdes (2015) as artes corporais permitem uma transformação humana individual dentro de um coletivo, tendo a capoeira um grande potencial de expressão corporal, o que favorece a transmissão de componentes afetivos e emocionais. Corroborando com essa ideia, os estudos demonstraram como resultado a construção de valores humanos, a boa convivência entre os indivíduos, a capoeira como espaço de exercício da cidadania, a autoestima, a construção de identidade, mudanças comportamentais e o cuidado com as relações interpessoais e intrapessoais, contribuindo de forma significativa para a formação de cada um como cidadão. Foi possível visualizar também o aumento da disposição dos alunos para trabalhos em grupos, o respeito e a valorização da individualidade de cada um, o fortalecimento das relações, o autocontrole, a disciplina, a criatividade e a autonomia. Entretanto, esses resultados devem ser analisados com cautela devido as limitações metodológicas apresentadas nos estudos incluídos.

\section{REFERÊNCIAS}

AREIAS, A. O que é capoeira. São Paulo: Brasiliense, 1983.

BARROS, K. F. O desenvolvimento da inteligência corporal cinestésica por meio da modalidade capoeira no primeiro ano do ensino médio. Revista Brasileira de Futsal e Futebol, São Paulo, v. 7, n. 27, p. 563-7, 2015.

BLUTEAU, R. Vocabulário português e latino. v. 4. Coimbra: Collegio das Artes da Companhia de Jesusus, 1713.

BRASIL. Lei $\mathbf{n}^{\circ} \mathbf{1 0 . 6 3 9}$, de 9 de janeiro de 2003. Estabelece a Diretrizes e Bases da Educação Nacional. Diário Oficial da União, Brasília, DF, 1996. Disponível em: <http://etnicoracial.mec.gov.br/images/pdf/lei 1063909012003. pdf>. Acessado em: 9 de setembro de 2020.

BRASIL. Ministério da Educação. Base Nacional Comum Curricular. Brasília, DF, 2017. Disponível em: <http://basenacionalcomum.mec.gov.br/images/ BNCC EI EF 110518 versaofinal site.pdf>. Acessado em: 12 de setembro de 2020.

BRASIL. Ministério da Educação. Portaria Normativa Interministerial $\mathbf{n}^{\circ}$ 17. 2007. Disponível em: <http://portal.mec.gov.br/arquivos/pdf/mais educacao.pdf>. Acessado em: 9 de setembro de 2020.

CAETANO, J.; ARRUDA, M. P.; BELLINATI, N. V. C. Contribuições da prática da capoeira no comportamento de alunos no ambiente escolar Revista Atlante Cuadernos de Educación y Desarrollo, Málaga, Revista Digital, julho, 2018. Disponível em: <https://www.eumed.net/rev/atlante/2018/07/praticacapoeira-alunos.html>. Acessado em: 30 de julho de 2020.

CARNEIRO, N. H.; GARCIA JÚNIOR, J. R. Aprendizagens da capoeira e desenvolvimento das capacidades físicas de pré-escolares por meio do lúdico. Colloquium Vitae, São Paulo, v. 2, n. 1, p. 1-8, 2010

CASTRO JÚNIOR, L. V.; ABIB, P. R. J.; SANTANA SOBRINHO, J. Capoeira e os diversos aprendizados no espaço escolar. Motrivivência, Florianóplois, v. 6, n. 14 , p. $160-170,2000$

FALCÃO, J. L. C. Para além das metodologias prescritas na educação física: a possibilidade da capoeira como complexo temático no currículo de formação profissional. Pensar a Prática, Goiânia, v. 7, n. 2, p. 155-70, 2004.

FREITAS, J. L. Capoeira na educação física: como ensinar? 3. ed. Curitiba: Progressiva, 2013 
GARDNER, H. Inteligências múltiplas: a teoria na prática. São Paulo: Artes Médicas, 1995.

GORITO, A. S.; ALVES, M.P. Escola Pública e Projeto Social: o cotidiano das aulas de Capoeira. Revista Latino-Americana de Estudos em Cultura e Sociedade, Rio de Janeiro, v. 5, n. 3, p. 1-20, 2019.

MARINHO, I. P. Subsídio para a história da capoeiragem no Brasil. Rio de Janeiro: Tupy, 1956.

MARTINS, L. D. R.; SANTOS, W.; MELLO, A. S.; VOTRE, S. F. Protagonismo infantil na educação física: uma experiência pedagógica com a capoeira. Revista Portuguesa de Educação, Braga, v. 29, n. 2, p. 1-17, 2016.

MOHER, D.; ALTMAN, D. G.; LIBERATI, A.; TETZLAFF, J. PRISMA statement. Epidemiology, Cidade, v. 22, n. 1, p. 128.

OLAECHEA, C.; GEORG, E. Arte e transformação social: o conhecimento e as práticas de criação valem a pena. Buenos Aires: CVLP, 2007.

PAULA, T. G.; BEZERRA, W. P. As vantagens do ensino da capoeira nas aulas de Educação Física escolar. Lecturas: Educación Física y Deportes, Buenos Aires, Revista Digital, v. 18, n. 188, 2014. Disponível em: <https://www. efdeportes.com/efd188/ensino-da-capoeira-nas-aulas-de-educacao-fisica. htm\#: :text=A\%20tem\%C3\%A1tica\%20Capoeira\%20pode\%20ser,\%2C\%20 Artes\%2C\%20Literatura\%20e\%20Geometria>. Acessado em: 23 de julho de 2021.

REGO, W. Capoeira de angola. Salvador: Itaporá, 1968.

SERBELO, R. A prática da capoeira dentro do ensino/aprendizagem com base na BNCC. Vitae Brasil, Planeta Educação. São Paulo, out. 2020. Disponível em: <https://www.plannetaeducacao.com.br/portal/inspiracao/ a/377/a-pratica-da-capoeira-dentro-do-ensinoaprendizagem-com-base-nabncc>. Acessado em: 24 de julho de 2021.

SOARES, C. E. L. Um rio de impérios e nações (resenha de Devotos da Cor). Estudos Afro-asiáticos, Rio de Janeiro, v. 24, p. 61-82, 1993.

SOUZA, F. P.; SOUZA, M. I.; TROIAN, M. L. Capoeira: contribuições pedagógicas para educação e inclusão curricular na escola municipal de educação básica Sadão Watanabe em Sinop - MT. Eventos Pedagógicos, Sinop, v. 3, n. 3, p. 80-90, 2012.

VALDES, E. R. A capoeira como ferramenta de inclusão social e inovação educacional: uma proposta para a disciplina educação física. Estudos Pedagógicos, Valdivia, v. 41, p. 193-212, 2015.

\section{AGRADECIMENTOS}

Os autores agradecem a Universidade de Sorocaba (UNISO) pelo incentivo à educação, pesquisa e extensão.

\section{CONFLITO DE INTERESSE}

Os autores do estudo declaram não haver conflito de interesse

\section{FINANCIAMENTO}

Este estudo não recebeu apoio financeiro.

\section{ORCID E E-MAIL DOS AUTORES}

Juliana Terra Ribeiro

ORCID: 0000-0003-0400-0035.

E-mail: julianaterrar@hotmail.com

Luis Felipe Milano Teixeira

ORCID: 0000-0002-7669-6011.

E-mail: teixeira.luisfelipe@gmail.com

Fabrício Teixeira Garramona (Autor Correspondente)

ORCID: 0000-0002-2140-5395.

E-mail: fabricio-tg@hotmail.com 